\title{
Resins for CAD/CAM Dentures
}

\author{
K Chandrasekharan Nair*, Pradeep C Dathan and T Mohankumar \\ Sri Sankara Dental College, Akathumuri, Trivandrum, Kerala, India \\ *Corresponding Author: Chandrasekharan Nair, Sri Sankara Dental College, \\ Akathumuri, Trivandrum, Kerala, India.
}

Received: February 10, 2021

Published: February 26, 2021

(C) All rights are reserved by Chandrasekharan Nair., et al.
Dentures fabricated by computer aided designing and manufacturing (CAD/CAM) process has a history of nearly three decades. Introduction of CAD/CAM marks a great departure from the conventional processing. Commonly used CAD/CAM techniques can be categorized into two:

- Subtractive or milling process.

- $\quad$ Additive or rapid prototyping process

\section{Subtractive or milling process}

The subtractive method involves a milling process of a pre polymerized PMMA blank by a computer numeric controlled (CNC) machine. The dental CNC machines consist of devices capable of multiaxis milling which facilitate 3D milling of dental restorations. The blank is produced under high temperature and pressure and hence has better mechanical properties. The biocompatibility profile of this material is almost equivalent to that of heat curing resin. AvaDent PMMA Puck is a popular brand of pre polymerized PMMA and the properties widely vary in different documentations: Conventional heat cure resin values are given in parenthesis:

- $\quad$ Flexural strength (MPa): $123.11 \pm 9.47$ (93.33 \pm 8.64$)$

- $\quad$ Flexural modulus (MPa): $2519.6 \pm 245.4$ (2117.2 \pm 154.3$)$

- Impact strength (kJ/m2): $24.556 \pm 2.633$ (14.756 2 2.106)

- $\quad$ Surface roughness(Ra-in $\mu \mathrm{m}): 0.37 \pm 0.03(0.12 \pm 0.29)$

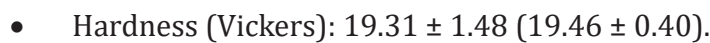

Higher flexural strength values of the CAD/CAM PMMA indicate lesser levels of voids and porosities present in the specimens. Flexural modulus indicates the stiffness and rigidity of a material. Flexibility of the denture base facilitates absorption of energy before fracture actually happens. However rigidity of the denture base ensures even distribution of forces to the underlying structures. Thinner dentures with comparatively better mechanical properties are expected with CAD/CAM dentures, which will improve patient compliance. Pre polymerized PMMA will be a better option for implant-supported over dentures, particularly when the inter arch space is very limited.

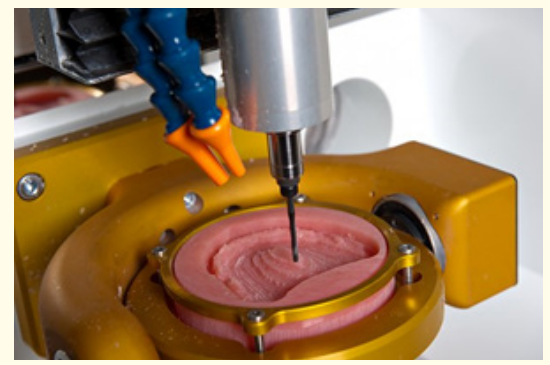

Figure 1: Milling of dentures: AvaDent denture being milled from a Lucitone 199®puck. (https://lmtmag.com/articles/technology_to_watch_avadenttrade_digital_dentures/photos)

Disadvantages of the milling technology is that it has limitations in reproducing complex morphologic features such as undercuts and the intaglio geometry of the dentures. If multiple copies of prosthesis are required, it becomes a time consuming process.

\section{Additive or rapid prototyping process}

Additive manufacturing is defined as the process of making objects through joining materials from 3D model data. This usually happens in a layering process. After a confirmed CAD design is obtained, the image is sliced into multiple segments. Every millimeter thickness of material, there will be 5-20 layers, which are laid down by the machine successively. When resin is used it is serially apposed over a support structure and subsequently curing it by one of the following methods: visible light, UV light, heat or laser. The layering and curing process is continued until the desired design is completely fabricated. 
In the additive system also, a CNC machine is used which has a processing head that moves in two axes viz. $x$ - and $z$-axes. Movement in the vertical axis ( $y$-axis) is achieved either by the specimen platform or by the processing head.

For dentistry and for industrial purposes, the following 3D printing methods are available.

- $\quad$ Stereolithography (SLA)

- $\quad$ Digital Light Processing (DLP)

- $\quad$ Electron Beam Melting (EBM)

- $\quad$ Fused Deposition Modeling (FDM)

- $\quad$ Laminated Object Manufacturing (LOM)

- $\quad$ Selective Laser Melting (SLM)

- $\quad$ Direct Metal Laser Sintering (DMLS)

The first two methods are popular with dental resins.

SLA process consists of a tank which is filled with liquid plastic photo-polymer resin. A flat build platform then slowly lowers into the tank and then very slowly rises causing the deposition of a thin resin layer of the design and which is subsequently traced out by a UV laser. As the UV Light passes, the deposited layer hardens. The build process is repeated along with the raising of the build platform until the part is completed.

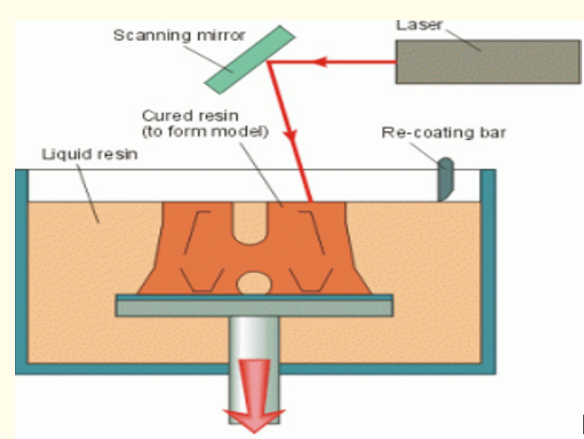

Figure 2: Stereolithography printing (adapted from 3D-printing expert.com)

DLP is a similar to stereolithography and it uses photopolymers. The major difference is in the light source. DLP uses a light source, such as an arc lamp with a liquid crystal display panel, which is applied to the entire surface of the vat of liquid resin in a single pass, so that the process becomes faster than that of SLA.
Digital light processing (DLP) is one of the most promising 3D printing technologies for dental applications because of its high resolution, rapid processing speed, and low cost. The light coming from a DLP projector of the 3D printer provides energy to polymerize the layers of the photosensitive material.

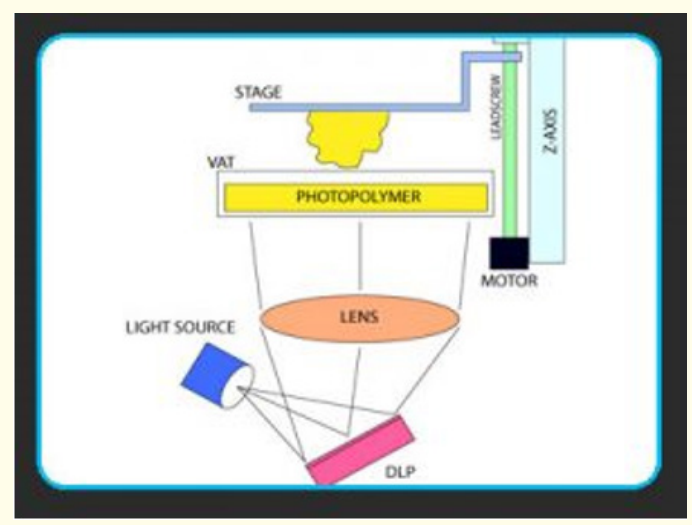

Figure 3: Digital light processing printing method (adapted from 3D-printing expert.com)

The formulation of 3D printing resins for dental use is greatly influenced by the choice of monomer. The use of monomers commonly found in the light-polymerized dental composite resins such as bisphenol A-glycidyl methacrylate (BisGMA) and urethane dimethacrylate (UDMA) is a realistic approach. Dimethacrylate monomers have high molecular weights and hence high viscosities, which can interfere with the process of printing. Therefore, nonhydroxylated monomers, such as ethoxylated bisphenol A-dimethacrylate (BisEMA), with a lower viscosity are good candidates. Otherwise, triethylene glycol dimethacrylate (TEGDMA) could be added as a diluent to decrease the viscosity of the printable resin. Resins with viscosities lower than $1500 \mathrm{cP}$ (centipoise) are usually selected for printing. Methacrylate-based photopolymerized resin is used for making artificial teeth. Documentation on the resins are very scarce. Published data on properties are as follows:

- $\quad$ Flexural strength 60 to $90 \mathrm{MPa}$

- $\quad$ Flexural modulus of 1.7 to $2.1 \mathrm{GPa}$

- Hardness(Vickers) 14 - $24 \mathrm{HV}$

Printing is used to fabricate common dental appliances like surgical guides, monolithic dentures, crowns and bridges, indirect bonding trays, clear aligners and dental models [1-5]. 


\section{Acknowledgement}

The authors gratefully acknowledge the internet resources for the figures used in the editorial

\section{Bibliography}

1. Ziad N Al-Dwairi., et al. "A Comparison of the Flexural and Impact Strengths and Flexural Modulus of CAD/CAM and Conventional Heat-Cured Polymethyl Methacrylate (PMMA)". Journal of Prosthodontics (2018): 1-9.

2. Murali Srinivasan., et al. "CAD/CAM milled complete removable dental prostheses: An in vitro evaluation of biocompatibility, mechanical properties, and surface roughness". Dental Materials Journal 37.4 (2018): 526-533.

3. Jaafar Abduo., et al. "Trends in Computer-Aided Manufacturing in Prosthodontics: A Review of the Available Streams". International Journal of Dentistry (2014): 15.

4. Chih-Hsin Lin., et al. "Mechanical properties, accuracy, and cytotoxicity of UV-polymerized 3D printing resins composed of BisEMA, UDMA, and TEGDMA, 2019". The Journal of Prosthetic Dentistry 123.4 (2020): 349-354.

5. https://3d-printing-expert.com/different-types-of-3d-printing-for-3d-printers /

\section{Assets from publication with us}

- Prompt Acknowledgement after receiving the article

- Thorough Double blinded peer review

- Rapid Publication

- Issue of Publication Certificate

- High visibility of your Published work

Website: www.actascientific.com/

Submit Article: www.actascientific.com/submission.php Email us: editor@actascientific.com

Contact us: +919182824667 